\title{
Optimists' Creed: Brave New Cyberlearning, Evolving Utopias (Circa 2041)
}

\author{
Winslow Burleson ${ }^{1} \cdot$ Armanda Lewis $^{1}$
}

Published online: 4 April 2016

(C) International Artificial Intelligence in Education Society 2016

\begin{abstract}
This essay imagines the role that artificial intelligence innovations play in the integrated living, learning and research environments of 2041. Here, in 2041, in the context of increasingly complex wicked challenges, whose solutions by their very nature continue to evade even the most capable experts, society and technology have co-evolved to embrace cyberlearning as an essential tool for envisioning and refining utopias-non-existent societies described in considerable detail. Our society appreciates that evolving these utopias is critical to creating and resolving wicked challenges and to better understanding how to create a world in which we are actively "learning to be" deeply engaged in intrinsically motivating experiences that empower each of us to reach our full potential. Since 2015, Artificial Intelligence in Education (AIED) has transitioned from what was primarily a research endeavour, with educational impact involving millions of user/learners, to serving, now, as a core contributor to democratizing learning (Dewey 2004) and active citizenship for all (billions of learners throughout their lives). An expansive experiential super computing cyberlearning environment, we affectionately call the "Holodeck," supports transdisciplinary collaboration and integrated education, research, and innovation, providing a networked software/hardware infrastructure that synthesizes visual, audio, physical, social, and societal components. The Holodeck's large-scale integration of learning, research, and innovation, through real-world problem solving and teaching others what you have learned, effectively creates a global meritocratic network with the potential to resolve society's wicked challenges while empowering every citizen to realize her or his full potential.
\end{abstract}

Winslow Burleson

wb50@nyu.edu

Armanda Lewis

al861@nyu.edu

1 New York University, New York, NY, USA 
Keywords Cyberlearning · Passion based learning · Creativity · Wicked problems · Artificial intelligence $\cdot$ Education

\section{Introduction}

In a manifesto published almost seventy years ago in 1972, UNESCO called for educational systems to provide opportunities that empower each and every individual to reach their full potential (Faure 1972). This treatise, "Learning to $\mathrm{Be}^{\prime \prime}$, created a global vision for the future of learning and technology. Since then, the UN has offered versions of the Millennial Goals in the 90's (Annan and Unies 2000) and 2015 (Nations 2015), eventually leading to the 2040 goals, which remarkably, have been met and in some cases surpassed. This achievement is due in no small part to advances in cyberlearning paradigms and implementations that have now been broadly adopted (Woolf 2010). In 2050, we will announce a new Vision for 22nd Century Millennial Goals, focusing on the remaining (known) "wicked problems," (Rittel and Webber 1974)- complex and large-scale challenges and opportunities likely to have an enduring influence on our societal transformations. These challenges range from climate change, to nuclear proliferation, to nanotechnology, synthetic biology, regional and global pandemics, the AI singularity, and many more (Levin et al. 2012). Today's cyberlearning-the tight coupling of cyber-technology with learning experiences offering deeply integrated and personally attentive artificial intelligence-is critical to addressing these global, seemingly intractable, challenges. Cyberlearning provides us (1) access to information and (2) the capacity to experience this information's implications in diverse and visceral ways. It helps us understand, communicate, and engage productively with multiple perspectives, promoting inclusivity, collaborative decision-making, domain and transdisciplinary expertise, self actualization, creativity, and innovation (Burleson 2005) that has transformative societal impact.

Cyberlearning has expanded from primarily attending to individual learners through a sequence of isolated problem solving activities, to embrace a rich array of collaborative experiential learning contexts, made possible by sophisticated and interconnected artificial intelligences. These include diverse and blended formal/informal learning environments, centers, resource networks, teams, communities, and ultimately global societies. Cyberlearning strives to ensure that each stakeholder is empowered to reach her or his full potential. To achieve this goal, AIED brings together diverse resources, virtual and physical instruments, simulations and models, and communities of practice to foster flow (and mitigate Stuck) (Burleson 2005), creativity, and wicked-problem deliberation. In the context of increasingly complex wicked challenges, whose solutions continue to evade even the most capable of experts, society and technology have co-evolved to embrace cyberlearning as an essential tool to envision, iteratively explore, and refine the evolution of our society, towards utopia.

Since 2015, Artificial Intelligence in Education (AIED) has transitioned from what was primarily an applied research endeavour operating with limited educational impact (effecting only a few million user/learners), to become a 
core contributor to our new paradigm of learning and living, made possible by the expansive experiential super computing cyberlearning environment - known as the Holodeck. Holdecks, over the past 25 years, have been instrumental to an important shift in the siloed nature of diverse societal engagements, resulting in broad adoption of an integrative approach to education, research, policy, and citizen engagement. Today, due in no small part to the collaborative and engaging nature of the Holodeck (See Fig. 1), we have achieved universal literacy and STEM literacy has quadrupled. Lifelong and life-wide passionbased learning have become global, high priority, all-hands-on-deck endeavours - enabling our entire global population to be involved, as diverse and key expert stakeholder participants, in advancing solutions to the grand challenges of our time.

\section{Evolving Utopia: Learning to Live and Learning to Be}

Today's longer life expectancies and increased access to integrated formal and informal learning opportunities (See Fig. 2) have expanded from 2005 categories (0-5, K, GR 1-12, UG, Grad, Work, and Retirement) to encompass a continuum, spanning the entire spectrum of life (Stevens and Bransford 2007). Blended formal and informal learning environments now provide as much as 75-100\% life-wide learning through experiences that leverage real-world contexts and authentic settings. Supporting increased opportunities for passion-based pursuits, there is universal access for individuals, teams, and communities, to a broad array of virtual and hands-on learning and innovation resources, e.g., high-end tools and

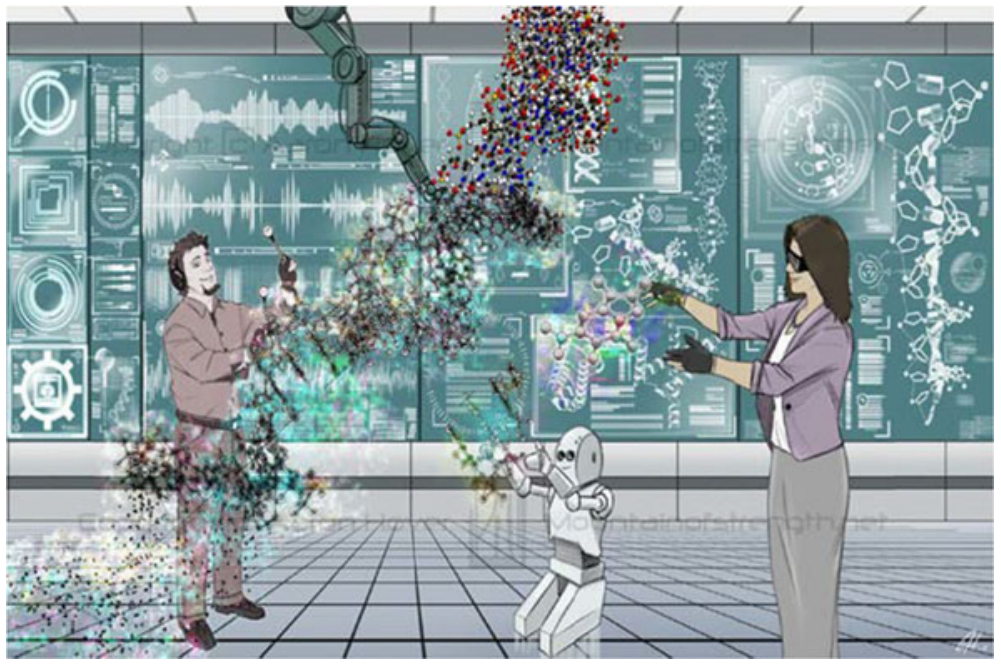

Fig. 1 The NYU-X Holodeck, the first Experiential Super Computer effort, integrated virtual, acoustic, physical, robotic, physiological, co-located, and distributed individual and team experiences into an advanced education, research, and innovation instrument 


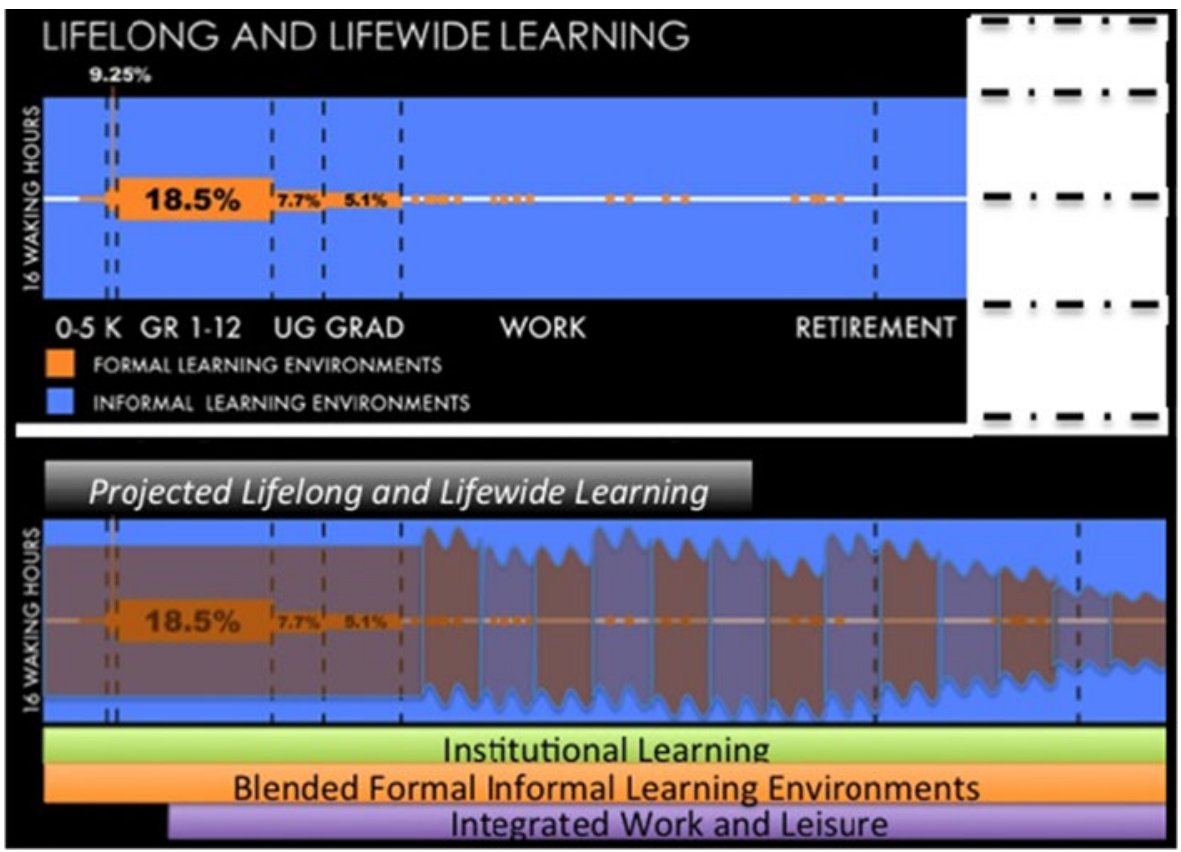

Fig. 2 Comparing Lifelong and Lifewide Learning in 2005 (top) with 2040 conditions superimposed (bottom) (Stevens and Bransford 2007)

expert mentors. Learning from peer and expert mentors and, reciprocally, being a mentor to peers and others, and becoming increasingly expert in one's own right are quintessential elements of today's learning and core elements of active citizenship. This eco-system provides low thresholds (lower barriers to entry), high ceilings (growth and impact potential), and wide walls (broad explorations and broad participation) (Resnick et al. 2005). Commensurately, there is no longer an emphasis on traditional retirement (Hiemstra 1999). Instead, we channel our energies into multiple lifelong and passion-based learning pursuits - engagements in and contributions to integrated education, research, and innovations that have broad societal impact (Foundation 2014). This lowering of institutional, programmatic, and life-stage boundaries, along with a concerted confluence of learning, career and leisure activity have convened to create rich and robust lifelong and lifewide growth experiences and actualizing opportunities.

Both lifelong and lifewide learning underpin the concept of "Learning to Live", referring to both learning how to thrive in a new and evolving range of contexts and circumstances, as well as providing the modus operandi for living as learning. Living has come to be embraced and appreciated as a rich experience of learning and growing, becoming, connecting, engaging energetically, exercising, teaching, mentoring, aspiring, discovering, exploring, fantasizing, daydreaming, and simply, in all its nuanced facets, "being" and learning to be! Learning to live is essential to the journey towards evolving utopia. 
As novice and expert learners engage with the Holodeck, they explore and create multifaceted experiences on multiple levels (fear, hate, love, insight, inspiration, flow and stuck, etc.) and learn to adopt and develop diverse and flexible perspectives (the obvious and the nuanced, the favoured and the marginalized) as they navigate possible worlds ${ }^{1}$ (Lewis 1977). Living in and creating these possible worlds, engages individuals in deep exploration of diverse utopias (i.e. non-existent societies described in considerable detail $^{2}$ (Wikipedia. Utopia 2015)). Our overarching goal is to understand the past and present as a foundation to help us imagine and evolve the future. Sophisticated imagining of the future can be an act of "living the future today" (Kelley 1997, Personal Communication https:/www.ideo.com/people/david-kelley) that helps us understand, re-solve, and begin to iteratively implement our collective aspirations for our 2041 world and its future.

Living within the fascinating, multitudinous, and consternating, Holodeck simulations (diverse possible utopias) require reflective metacognition. This experience is purposely perplexing. It is perplexing in that there are so many challenges, so many opportunities, and so many seeming unresolvable wicked challenges. Nonetheless, we embrace this perplexity as desirable. We have evolved a broad consensus that the best way to handle wicked challenges is to develop a series of incremental iterative solutions, a process known as the re-solving (Lewis 1977) of ongoing challenges. We achieve this via sophisticated scenario development and committed engagement in the rich and diverse stories (simulated and real) of living in utopia. In this context, exploration and deliberation within the Holodeck is not only a hallmark of cyberlearning, but also enhances the capacity of our global community to collaboratively create and implement the iterative re-solutions required to solve our wicked challenges.

To reach our full potential and to succeed at re-solving wicked challenges, we need to be exploratory, creative, and to develop our diverse, individual and collective expertise. Schank posited that when the walls can answer questions, those that learn the most are the ones with the best series of questions (Brockman 2007). Expanding on this, in the context of the Holodeck, we have found that when individuals and teams of learners actively engage in hands-on collaborative activities, they begin to understand things from multiple perspectives-they begin to become experts (Burleson 2005; Kay 1991). In these environments, key elements of Amabile's componential model of creativity: intrinsic motivation; domain expertise; creative style (Creativity Support Tools (Resnick et al. 2005) and tools for reflective engagement); and actualizing resources, coalesce to advance individual and team creative processes and outcomes (Amabile 1983). By definition, creativity - anything new, non-obvious, and useful - is responsible for all societal advancement (Burleson 2005). Thus, with creative exploration and ever more sophisticated expertise, the goals of cyberlearning, AIED, and the Holodeck are to facilitate learning to live, learning to be, and living in and evolving utopia.

\footnotetext{
${ }^{1}$ David Lewis' philosophy of possible worlds argues simply imagining a possible world means that it can actually exist.

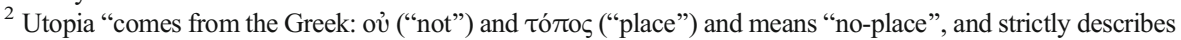
any non-existent society "described in considerable detail'." (Ref. Wiki) In English Eutopia ("good" or "well") is homophonous with Utopia and may have lead to the original meaning being obscured by the more idealistic relative.
} 


\section{Today's Cyberlearning Features, Utopia and Wicked Challenges}

Evolving utopia and iteratively re-solving wicked challenges are critical to cyberlearning and advancing society. The primary qualities of the brave new cyberlearning environments of today, include:

Personal stories and interactive experiences that make it rich - The magic of humanity has been our dreams, our exploration and fulfilment of dreams, and our complex story telling (Sagan 1985). These dreams are core to our ethical and philosophical understanding and to our appreciation of our historical heritage. Learning has evolved from ancient toys and board games, to embedded cyberlearning phenomena (Moher 2006) such as Real World Games (Waern et al. 2009; Rashid et al. 2006; Burak et al. 2005; McGonigal 2011) and personalized environments (Lahey et al. 2008; Mahoney et al. 2014); the ability for individual (Papert 1980) and communal (Resnick et al. 2009) appropriation of these is appreciated as being core to the reflection (Shneiderman 2003) and feedback loops that help people learn and help creative societies evolve.

Open streaming content that make it real and compelling - Multi-modal modeling simulation and real world prediction provide visceral qualities that empower learners to feel experiences, as they react to immersive worlds and understand (on multiple levels) the implications. In the context of simulation, it is possible to "turn on" and "turn off" complexity to access the diverse array of realworld and "open world" data sources in real-time and asynchronously. We can fly drones over Antarctica, and under the ice into ancient lakes (Berenfeld 1996) or obtain data from the LEGO robots on the moon and international instruments on Mars and beyond the solar system (Burleigh et al. 2003).

Contributions that make it yours, together - All participants take active ownership of their learning, and living experiences. Learners, peer tutors, and mentors (learners and teachers of all ages and stages) are empowered to creatively embark on their own learning trajectories, to reflect on these, and to share their insights and contributions broadly. This empowering ecosystem is fundamental to developing: (1) robust expertise; (2) deep collaborations; and (3) strong communication skills, both within and across domains. Core to today's cyberlearning is the ability to actively learn and teach effectively, within and across individual and global communities.

Wicked challenges that can be iteratively "re-solved" - Rittel introduces the notion of solving again and again, of re-solving wicked challenges, as being the iterative and collaborative attempt to inch ever closer towards addressing the complexity intrinsic to these challenges (Rittel and Webber 1974). Since this inherently requires multi-generational understanding, our advancement of utopia requires levels of engagement, dedication, and persistent, life-long hard work, coupled with the richness and actualization of deep play (Ackerman 2011). Making progress in addressing and overcoming the complex wicked challenges that face our society, e.g., climate change, disease/bio-resilience, unintended consequences (economic stability, volatility, "progress") etc., is highly rewarding and truly significant. As we embrace the wisdom of our elders, we are compelled to equip our next generation with the best of our understanding, abilities, and tools, to help 
them take a long perspective and to equip them with the most effective tools that we can provide, to "leave the future with a free hand" (Feynman 1955). We strive to achieve these goals in the midst of an on-going range of wicked challenges and their own inherent interconnectedness. Much work is still needed to solidify, scale, penetrate, and adopt the evolving re-solutions; though there are great risks, there is substantial support, and great potential reward.

\section{Recognizing the Merits of Advanced Cyberlearning}

Twenty-five years ago, American educators and learning scientists experienced a critical moment in their history, as their nation's preparedness and leadership in STEM innovation faced a range of internal and external challenges. U.S. high school students ranked lower on math and science scores than peers in $46 \%$ and $34 \%$ of OECD countries, respectively ((PISA), P.f.I.S.A. 2012); and China had overtaken the U.S. in the number of patents filed (Gurry et al. 2014). At the same time, the structure and economic models underpinning American higher education were undergoing a massive transformation (Hirsch and Weber 2002). Grade inflation and market forces were threatening the quality of higher education in America and her role in leading the globe in advanced education was being called into question (Arum and Roksa 2011). Supposed experts, graduating with bachelors, masters, and doctoral degrees from even the most acclaimed institutions were increasingly incapable of: (1) comprehensively understanding and solving meaningful problems in their own domains; (2) working with colleagues across disciplines and across cultures; and (3) effectively communicating the value of their fields and engaging a broad public audience - a public, comprised of diverse stakeholders, in dire need of comprehending a wide range of increasingly complex matters. Compounding this situation was an evolving, though not yet universal, appreciation that dramatic advancements in technology, increasing complexity of society, and the disastrous effects of unintended consequences presented a context in which "wicked challenges" (Rittel and Webber 1974) were becoming ever more complex (Levin et al. 2012).

The increased access and capacity offered by these emerging technologies, coupled with the motivating influence of pressing wicked challenges led to increased recognition of the importance of integrated transdisciplinary education and research, as fertile ground for discovery, creativity, and innovation. These activities are now seen as critical to realizing the full potential of each and every individual; a means of enhancing national capacities; and as having the power to foster global, democratic, access to universal lifelong learning opportunities. Researchers and practitioners developed translational learning science innovation centers (Duderstadt 2010) to ensure that society would be equipped with cyberlearning strategies and tools with the capacity to overcome the siloed cultures of the academy and education sector, that could bridge gaps with industry and the public, and empower dreams that begin to realize our collective true potential. This served as both a fundamental investment and a societal commitment to building an open and participatory utopia. 
For the first decade of the millennium, the AIED community generally held that the gold standard of advanced cyberlearning technology was an Intelligent Tutoring System (ITS) capable of achieving comparable results to those from one-on-one interaction with a human tutor. Today, a new gold standard has emerged. It is based on the broad appreciation of the transformative potential and transdisciplinary depth and breadth of both individuals and teams, working in dynamic, co-located, and distributed configurations with the common goal of empowering lifelong learning and achievement. Two Computing Research Association Grand Challenges for Information ScienceProviding a Teacher for Every Learner and A Team (team of human, agent, and robotic collaborators) of One's Own (Association, C.R. 2003) -were merged to create a multifaceted initiative to advance human development through enquiry, exploration, discovery, and innovation. This initiative has facilitated a new generation of cyberlearning technologies that fuses hybrid (physical and digital) experiences with advanced understanding of the psychology of individual and team learning, affect, social interaction, motivation, and creativity. Hybrid experiences are made possible by rich media, content, and advanced tools. Psychology has advanced over this period, using multimodal sensors and machine-learning techniques to create a sophisticated fusion of theory and practice to provide just-in-time, individualized, and team support.

During the early 2000 s, large-scale learning research was generally limited to indepth observation of a few learners or coarse-grained measures of learning outcomes for larger groups. The state-of-the-art cyberlearning tools that have emerged can now augment learning research with capabilities, such as: multi-modal formative and summative assessments to iteratively determine the zone of proximal development; sensing of cognitive load and affect; integrated real-time feedback that fosters metacognition; and utilization of attribution, cognitive aids, and stress inoculation, to personalize support that improves individual, collaborative, and collective decisionmaking processes, learning, and creativity. For example, mid-21st-century cyberlearning environments are fusing immersive environments with peer learning companions (including both virtual and robotic social agents). This blending of multimedia and physical agents encourage embodied actions and gestural interactions, and empower learners and active citizens to explore and manage complex environments (Hodges 2012), adopt systems thinking strategies, and engage in team collaboration to address societal challenges.

\section{Holodecks: Experiential Super Computers for Cyberlearning}

In the early 2000s, workshops sponsored by the Computing Community Consortium (CCC), Computing Research Association (CRA), and National Science Foundation (NSF) Global Resources for Online Education (GROE) program advanced a Roadmap for Education Technology. This strategic plan included a research strategy for rich interfaces (Woolf 2010) (see Table 1).

Appreciating GROE's vision of rich interfaces, the NYU-X initiative (NYU-X 2015) and its consortium of public and private institutional partners advanced first and second-generation experiential super computers_- "Holodecks" (see Fig. 1). For the past 20 years, NYU-X has iteratively created a sophisticated suite of rich interfaces. Today, our global network of experiential super computers, broadly accessible through 
Table 1 CCC, CRA, and NSF 2010 GROE Workshop Roadmap for Education Technology Vision for Rich Interfaces (circa 2030)

Interface capabilities

2030 Vision

Affect \& emotion recognition

Embodied interactions

Learning companions

Brain-computer interfaces

Physiological

Augmented reality

Haptic
Strong recognition, fluent expression highly personalized

Full body capture everywhere; mirroring behavior

Virtual + robotic companions that seamlessly switch between virtual and physical settings

Continues wearable, fMRI-like capability' and EEG / Near Infra Red signals

In-body monitoring and tranmission - oxygen, glucose and cortisol indicators; HR/Breath

Seamless, natural, ubiquitous, recognition

Enhanced mobility, super hero capability high power haptic capabilities

common low-end consumer electronic devices, provides a democratic foundation for integrative approaches to cyberlearning, grand challenge innovation, and wicked problem solving.

The Holodeck is the foundation of today's cyberlearning experience, offering a software/hardware instrument that seamlessly integrates visual, audio, and physical (haptics, objects, real-time fabrication) components with novel technologies. This system enhances social interactions (human-human, human-agent, and human-robot) by creating a powerful, unified education and research environment and network. Capabilities support capture of comprehensive behavioural, physiological, affective, and cognitive data; visualization; real time analysis of the data; and sophisticated scenario modeling and engagement.

The initial NYU Holodeck balanced opportunities for small group, cross-site collaboration and research with incremental equipment costs. Included were "field kits" capable of global distributed support for single users or specialized interaction by multiple participants. The NYU Holodeck (NYU-X 2015) infrastructure linked many other facilities, like the BeingThere Lab (BeingThere Center 2015; Raskar et al. 1998), ASU Decision Theater (Theater 2015), UCSB AlloSphere (Kuchera-Morin et al. 2014), and Stony Brook Reality Deck (Papadopoulos et al. 2015) to advance what was at the time, state-ofthe-art rendering of complex real-time scenarios and contingencies. By 2030, this project architecture had paved the way for infrastructure improvements that supported thousands of simultaneous users.

Today's Holodeck thrives upon the evolution of the internet, creating a global network that is fundamentally accessible as a human right (Nations $2011)$ to the entire global population ( $\sim 10$ billion people). The network connects approximately a trillion devices-the internet of things, each with their own embedded intelligence and autonomy, spanning all sectors of enterprise and society and extending initially throughout, and now beyond the solar system (CISCO 2011). Fundamentally, the Holodeck's well-integrated multimodal capabilities serve as a dynamic engine for the core tenants of "Learning to $\mathrm{Be}^{\text {"; }}$ functionality includes: 
Visual - Visual hardware has evolved to provide high-resolution, low latency, immersive, and distributed VR interactivity. Multimodal mesh peer-topeer and peer-to-network connectivity is the framework for globally- distributed communication and engagement. Low-cost embedded cameras have become default acquisition tools, enhanced with algorithms to detect context-based facial expressions, gestures, and social dynamics. Likewise, distributed sensors support a broad range of environmental analysis and scientific experimentation.

Acoustic-The distributed audio capabilities can capture and recreate almost any auditory environment using simulated or pre-recorded sounds from repositories and generative algorithms, linking learners with musicians and performers, and sound-effect experts, in distributed engagements around the world in real time.

Physical - Smart objects, digital-manipulatives, and robotic interfaces are some of the rich interfaces the Holodeck has evolved. These expand upon Tangible User Interfaces (TUIs) such as Sandscape (Ishii et al. 2004) and malleable interfaces such as programmable matter (Gilpin and Rus 2013) and digital clay (Rossignac et al. 2003). Simulation tools, customized user interfaces (e.g., aviation yolks, steering wheels, command centers, and glass cockpits), and a range of robotic platforms have become available for collocated and/or distributed remote interaction (5Ds of robotics e.g., for dirty, dull, dangerous, domestic and dexterous engagement). Likewise, haptic interfaces (data gloves) and 3D fabrication tools have been combined to enhance creative generative experiences and exploration. These tools provide added reality dimension to virtual experiences, and have made us aware of previously unknown or underappreciated aspects of our environment.

Human Dynamics: Biometric - Sophisticated multimodal sensing capabilities include eye-tracking (wearable/mobile, at a distance, and multi-person), multi-touch pressure sensors, Brain Computer Interaction (BCI), and affective and sociometric sensors and algorithms (Burleson 2005; Arroyo et al. 2009; Tripathi and Burleson 2012). A high quality camera array-based motion capture system synchronously and asynchronously acquires, analyses, classifies, and streams spatio-temporal data from a wide variety of kinematic sources (individual or groups of human bodies/faces, robotic mechanisms, rigid object "props", etc.). These rich data sets drive customizable animations and other displays and extrapolate data from nonverbal expressions. Research locations are linked with seamless and instantaneous (within our latest understanding of the "laws of physics") transmission of data and visualizations.

Human Dynamics: Social Collaboration - The Holodeck offers enhanced social collaboration, co-located and distributed human-human, human-agent, and/or human-robot interaction capabilities. Customizable virtual agents and social robots equipped with advanced technology interact using natural language, mirror rich emotive facial gestures, and reflect social characteristics that synchronize speech and gesture production. Integrated agents and surrounding hardware/software create rich multimodal environments with 
the capacity for real-time data modelling of individual and team behaviours, interactions, team creativity, and collocated and distributed knowledge (wisdom of crowds and expert systems, e.g., IBM's Watson (Ferrucci et al. 2013)). These are coupled with lifelong and lifewide personal, team, and community learning portfolios that provide rich and open learner models and data resources for understanding effective collaboration, teamwork, and communal deliberation.

Infrastructure: Network, Communication and Collaboration - A "data as service" model has created a multi-site, node-based, hybrid, maximally transparent AR/VR space that features high quality, multimodal tracking and collaboration. High-bandwidth connections between local and central nodes are supplemented with low latency networks that seamlessly and reliably scale on demand. The open source platform of real-time APIs supports real-time sharing and data control. Field kits link remote sites with select functionality to provide data, interactivity, and share resources with the networked instrument and Holodeck infrastructure, while reducing their own computational requirements, complexity, and cost.

\begin{tabular}{ll}
\hline $\begin{array}{l}\text { Element } \\
\text { Visual }\end{array}$ & $\begin{array}{c}\text { Description } \\
\text { Multimodal mesh networks provide peer-to-peer and peer-to-network connectivity creating } \\
\text { the framework for globally- distributed visual communication and engagement. }\end{array}$ \\
Acoustic & $\begin{array}{c}\text { Audio capabilities include distributed technologies that can create almost any auditory } \\
\text { environment using captured, generated, or pre-recorded sounds. }\end{array}$ \\
Physical & $\begin{array}{l}\text { Smart objects, digital-manipulatives, and robotic interfaces enable rich interactions } \\
\text { an imaginative explorations. }\end{array}$ \\
Human Dynamics & $\begin{array}{c}\text { Aggregates biometric, social interaction, crowd source wisdom and expert systems } \\
\text { along with rich learning portfolios and models of collaborative understanding. }\end{array}$ \\
Infrastructure & $\begin{array}{c}\text { Provides a robust modular system that can evolve and adapt to technological } \\
\text { advances and refinement. }\end{array}$ \\
\hline
\end{tabular}

Cyberlearning research afforded by experiential supercomputing has scaled through mobile, hand-held, and distributed devices to broadly impact education and daily living. As robust, consumer-grade VR hardware, digital manipulatives, and low-cost robotic and fabrication platforms emerged, cyberlearning research and infrastructure was revolutionized. The result was findings with transformative impact on formal and informal learning environments (classrooms, museums, homes, communities, nations, and our international community) across the entire socioeconomic spectrum.

\section{Conclusion}

We are proud of what we have achieved, and are cautiously optimistic for what our future holds. We have made tremendous progress since the early days of the ideal cyberlearning environment that began with individual intelligent tutoring systems and built on existing classroom-based activities. Today's interfaces provide ubiquitous connectivity and universal access to comprehensive experiential learning, discovery 
and innovation that can support all manners of inquiry and endeavors. In 2040, learning is unlimited - each individual can create a teacher, team, country, world, galaxy or universe of their own. We have created an environment where we can imagine possible worlds and experiences to help us re-solve the wicked challenges whose solutions will shape our continuing evolution. There is no question that we must learn a great deal more as we continue to champion optimism and democratic exploration. The future belongs to us all and we are motivated by our responsibility to continue our evolution toward utopia.

Acknowledgments We are grateful to the entire NYU HoloDeck team for their involvement in advancing the rich array of technologies and experiences that are core to realizing and evolving the promise of an advanced experiential super computer.

\section{References}

(PISA), P.f.I.S.A.(2012) Selected Findings from PISA 2012.

Ackerman, D. (2011). Deep play. New York: Vintage.

Amabile, T. M. (1983). The social psychology of creativity: A componential conceptualization. Journal of Personality and Social Psychology, 45(2), 357.

Annan, K. A., \& Unies, N. (2000). We the peoples: the role of the United Nations in the 21st century. New York: United Nations, Department of Public Information.

Arroyo, I., Cooper, D. G., Burleson, W. Woolf, B. P., Muldner K., \& Christopherson, R.(2009). Emotion sensors go to school. InAIED, 200, 17-24.

Arum, R., \& Roksa, J. (2011). Academically adrift: Limited learning on college campuses. Chicago: University of Chicago Press.

Association, C.R. (2003). Grand research challenges in information systems. in A conference Series on Grand Research Challenges in Computer Science and Engineering.

BeingThere Center. (2015); Available from: <span style = "font-size:12.0 ptAvailable from: mso-bidi-language:AR-SA">http://beingthere.web.unc.edu/.

Berenfeld, B. (1996). Linking students to the infosphere. THE Journal (Technological Horizons In Education), 23(9), 76.

Brockman, J. (2007). The next fifty years: Science in the first half of the twenty-first century. New York: Vintage.

Burak, A., Keylor, E., \& Sweeney, T. (2005). PeaceMaker: A video game to teach peace. In M. Maybury, O. Stock, \& W. Wahlster (Eds.), Intelligent Technologies for Interactive Entertainment (pp. 307-310). Berlin: Springer-Verlag.

Burleigh, S., et al. (2003). Delay-tolerant networking: an approach to interplanetary internet. IEEE Communications Magazine, 41(6), 128-136.

Burleson, W. (2005). Developing creativity, motivation, and self-actualization with learning systems. International Journal of Human-Computer Studies, 63(4), 436-451.

CISCO. 2011; Available from: <span style = "font-size:12.0 ptAvailable from: mso-bidi-language:ARSA">http://www.iotsworldcongress.com/documents/4643185/3e968a44-2d12-4b73-9691-17ec508ff67b.

Dewey, J. (2004). Democracy and education. New York: Courier Dover Publications.

Duderstadt, J. J. (2010). Engineering for a changing world, in Holistic Engineering Education (pp. 17-35). New York: Springer.

Gurry, F., et al. (2014). World Intellectual Property Indicators. Switzerland: World Intellectual Property Organization.

Faure, E. (1972), Learning to be: The world of education today and tomorrow. Paris: Unesco.

Ferrucci, D. A., et al. (2013). Watson: beyond jeopardy! Artificial Intelligence, 199, 93-105.

Feynman, R. P. (1955). The value of science. Engineering and Science, 19(3), 13-15.

Foundation, N.S. (2014). National science foundation: investing in science, engineering, and education for the nation's future: strategic plan, 2014-2018.

Gilpin, K. W., \& Rus, D (2012). What's in the bag: A distributed approach to 3d shape duplication with modular robots. Robotics Science and Systems, 2012, 89-96.

Hiemstra, G. (1999). The End of retirement is near, in futurist. http://www.futurist.com/articles-archive/theend-of-retirement-is-near/.

Hirsch, W.Z. and L. Weber (2002) As the walls of academia are tumbling down. Economica Limited. 
Hodges, K. V. (2012). Solving complex problems. Science, 338(6111), 1164-1165.

Ishii, H., et al. (2004). Bringing clay and sand into digital design-continuous tangible user interfaces. $B T$ Technology Journal, 22(4), 287-299.

Kay, A. C. (1991). Computers, networks and education. Scientific American, 265(3), 138-148.

Kuchera-Morin, J., et al. (2014). Immersive full-surround multi-user system design. Computers \& Graphics, $40,10-21$.

Lahey, B., et al. (2008) Integrating video games and robotic play in physical environments. in Proceedings of the 2008 ACM SIGGRAPH symposium on Video games. ACM.

Levin, K., et al. (2012). Overcoming the tragedy of super wicked problems: constraining our future selves to ameliorate global climate change. Policy Sciences, 45(2), 123-152.

Lewis, D. (1977). Possible-world semantics for counterfactual logics: A rejoinder. Journal of Philosophical Logic, 6(1), 359-363.

Mahoney, D., et al. (2014). Development of a responsive emotive sensing system (DRESS) to aid persons with dementia dress independently. Gerontechnology, 13(2), 259.

McGonigal, J. (2011). Reality is broken: Why games make us better and how they can change the world. New York: Penguin.

Moher, T. (2006).Embedded phenomena: supporting science learning with classroom-sized distributed simulations. in Proceedings of the SIGCHI conference on human factors in computing systems. ACM.

Nations, U. 2011. http://www2.ohchr.org/english/bodies/hrcouncil/docs/17session/A.HRC.17.27 en.pdf.

Nations, U. (2015). UN report, millennium development goals. http://www.un.org/millenniumgoals/2015 MDG Report/pdf/MDG\%202015\%20rev\%20(July\%201).pdf.

NYU-X. 2015; Available from: <span style = "font-size:12.0 ptAvailable from: mso-bidi-language:ARSA">http://www.nyu-X.org.

Papadopoulos, C., et al. (2015). The Reality Deck-an Immersive Gigapixel Display. IEEE Computer Graphics and Applications, 35(1), 33-45.

Papert, S. (1980) Mindstorms: Children, computers, and powerful ideas. Basic books, Inc, New York.

Rashid, O., et al. (2006). PAC-LAN: mixed-reality gaming with RFID-enabled mobile phones. Computers in Entertainment (CIE), 4(4), 4.

Raskar, R., et al. (1998) The office of the future: A unified approach to image-based modeling and spatially immersive displays. in Proceedings of the 25th annual conference on Computer graphics and interactive techniques. ACM.

Resnick, M., Myers, B., Nakakoji, K., Shneiderman, B., Pausch, R., Selker, T, \& Eisenberg, M (2005). Design principles for tools to support creative thinking. Report of Workshop on Creativity Support Tools, http:// www.cs.umd.edu/hcil/CST/report.html

Resnick, M., et al. (2009). Scratch: programming for all. Communications of the ACM, 52(11), 60-67.

Rittel, H., \& Webber, M. (1974). Wicked problems. Man-Made Futures, 26(1), 272-280.

Rossignac, J., Allen, M., Book,W.J., Glezer, A., Ebert-Uphoff, I., Shaw, C., Rosen,D., et al. (2003). Finger sculpting with digital clay: $3 \mathrm{~d}$ shape input and output through a computer-controlled real surface. In Shape Modeling International (pp. 229-231). Washington, DC: IEEE Computer Society

Sagan, C. (1985). Contact: a novel. New York: Simon and Schuster.

Shneiderman, B. (2003). Leonardo's laptop: human needs and the new computing technologies. Cambridge: Mit Press.

Stevens, R., \& Bransford, J. (2007). The LIFE Center's lifelong and lifewide diagram. Learning in and out of school in diverse environments: Life-long, life-wide, life-deep. Seattle: University of Washington Center for Multicultural Education.

Theater, A.D. (2015); Available from: <span style = "font-size:12.0 ptAvailable from: mso-bidi-language:ARSA">http://www.asu.edu/feature/includes/spring05/readmore/dt.html.

Tripathi, P. and W. Burleson (2012). Predicting creativity in the wild: Experience sample and sociometric modeling of teams. in Proceedings of the ACM 2012 conference on Computer Supported Cooperative Work. ACM.

Waern, A., M. Montola, and J. Stenros (2009). The three-sixty illusion: designing for immersion in pervasive games. in Proceedings of the SIGCHI Conference on Human Factors in Computing Systems. ACM.

Wikipedia. Utopia (2015). Available from: <span style = "font-size:10.0 ptAvailable from: mso-fareast-fontfamily:"Times New Roman"“>https://en.wikipedia.org/wiki/Utopia\%3Cspan style = "font-size:10.0 pt.

Woolf, B. P. (2010). A roadmap for education technology. Report of the Computing Research Association, http://cra.org/ccc/wp-content/uploads/sites/2/2015/08/GROE-Roadmap-for-Education-Technology-FinalReport.pdf 